\title{
Resonance Propagation and Elimination in Integrated and Islanded Microgrids
}

\author{
K. V. Siva Reddy ${ }^{1}$, SK. Moulali ${ }^{2}$, K. Harinadha Reddy ${ }^{3}$, Ch. Rami Reddy ${ }^{4}$, B. V. Rajanna ${ }^{5}$, \\ G. Venkateswarlu ${ }^{6}$, Ch. Amarendra ${ }^{7}$ \\ ${ }^{1,2,4,5,7}$ Department of Electrical and Electronics Engineering, K L E F, A.P., India \\ ${ }^{3}$ Department of EEE, Lakireddy Bali Reddy College of Engineering (Autonomous), Mylavaram, A.P., India \\ ${ }^{4,6}$ Department of EEE, Nalanda Institute of Engineering and Technology, Guntur, A.P., India \\ ${ }^{7}$ Department of EEE, Adithya Engineering College (Autonomous), Surampalem, A.P., India
}

\begin{tabular}{l} 
Article Info \\
\hline Article history: \\
Received Apr 7, 2018 \\
Revised Aug 1, 2018 \\
Accepted Aug 12, 2018 \\
\hline Keyword: \\
Active power filter \\
Distributed power generation \\
Droop control \\
Grid-connected converter \\
Resonance propagation \\
Virtual impedance
\end{tabular}

Ch. Rami Reddy, Department of Electrical and Electronics Engineering,

K. L. Education Foundation,

Green fields, Vaddeswaram, Guntur, Andhra Pradesh, India.

Email: crreddy229@gmail.com

\begin{abstract}
In this paper, a micro grid resonance propagation model is investigated. To actively mitigate the resonance using DG units, an enhanced DG unit control scheme that uses the concept of virtual impedance is proposed. It can be seen that a conventional voltage-controlled DG unit with an LC filter has a shortcircuit feature at the chosen harmonic frequencies, whereas a currentcontrolled DG unit presents an open-circuit characteristic. The application of underground cables and shunt capacitor banks may introduce power distribution system resonances. This paper additionally focuses on developing a voltage-controlled DG unit-based active harmonic damping technique for grid-connected and islanding micro grid systems. An improved virtual impedance control method with a virtual damping resistor and a nonlinear virtual capacitor is proposed. The nonlinear virtual capacitor is used to compensate the harmonic dip on the grid-side inductor of a DG unit LCL filter. The virtual resistance is principally answerable for micro grid resonance damping. The effectiveness of the proposed damping method is examined using each a single DG unit and multiple parallel DG units.
\end{abstract}

Copyright $(9) 2018$ Institute of Advanced Engineering and Science. All rights reserved.

\section{INTRODUCTION}

The increasing application of nonlinear loads can lead to significant harmonic pollution in a power distribution system. The harmonic distortion might excite complicated resonances, particularly in power systems with underground cables or sub sea cables [1]. In fact, these cables with nontrivial parasite shunt capacitance will form an LC ladder network to amplify resonances. In order to mitigate system resonances, damping resistors or passive filters can be placed in the distribution networks. However, the mitigation of resonance propagation exploitation passive components is subject to some well understood problems, like power loss and additional investment [2]. Moreover, a passive filter might even bring extra resonances if it's designed or installed without knowing detailed system configurations. To avoid the adoption of passive damping equipment, numerous types of active damping methods are developed [3-6]. Among them, the resistive active power filter (R-APF) is often considered as a promising way to understand better performance. Conventionally, the principle of R-APF is to emulate the behavior of passive damping resistors by applying a closed-loop current-controlled method (CCM) to power electronics converters [7-8]. In this management category, the R-APF will be simply modeled as a virtual harmonic resistor if it's viewed at the distribution system level, in addition, many changed R-APF [9-13] ideas were additionally developed in the 
recent literature. In, the separate tuning method was proposed to regulate damping resistances at different harmonic orders. For current-controlled $\mathrm{dg}$ units, the auxiliary R-APF function can be seamlessly incorporated into the primary $\mathrm{dg}$ real power injection function by modifying the current reference [14]. However, conventional CCM will hardly provide direct voltage support throughout the micro grid islanding operation. To beat this limitation, an enhanced voltage-controlled method (VCM) was recently proposed for dog units with high-order LC or LCL filters [15-17]. It can be seen that the control method of regulating the DG unit as virtual impedance, that is dependent on the present feeder electric resistance. Once the feeder electric resistance is inductive, this method could not provide enough damping effects to system resonance.

\section{RESEARCH METHOD}

Figure 1 illustrates the configuration of a single-phase micro grid system, where a few DG units are interconnected to the point of common coupling (PCC) through an extended underground feeder. For the sake of simplicity, this paper only adopts an easy micro grid configuration to demonstrate how the micro grid power quality is affected by resonance propagation. In addition, this paper also assumes that shunt capacitor banks and parasitic feeder capacitances are equally distributed in the feeder. Note that the static transfer switch (STS) controls the operation mode of the micro grid, when the main grid is disconnected from the micro grid, the PCC nonlinear loads shall be supplied by the standalone DG units. Tables and Figures are presented center, as shown below and cited in the manuscript.

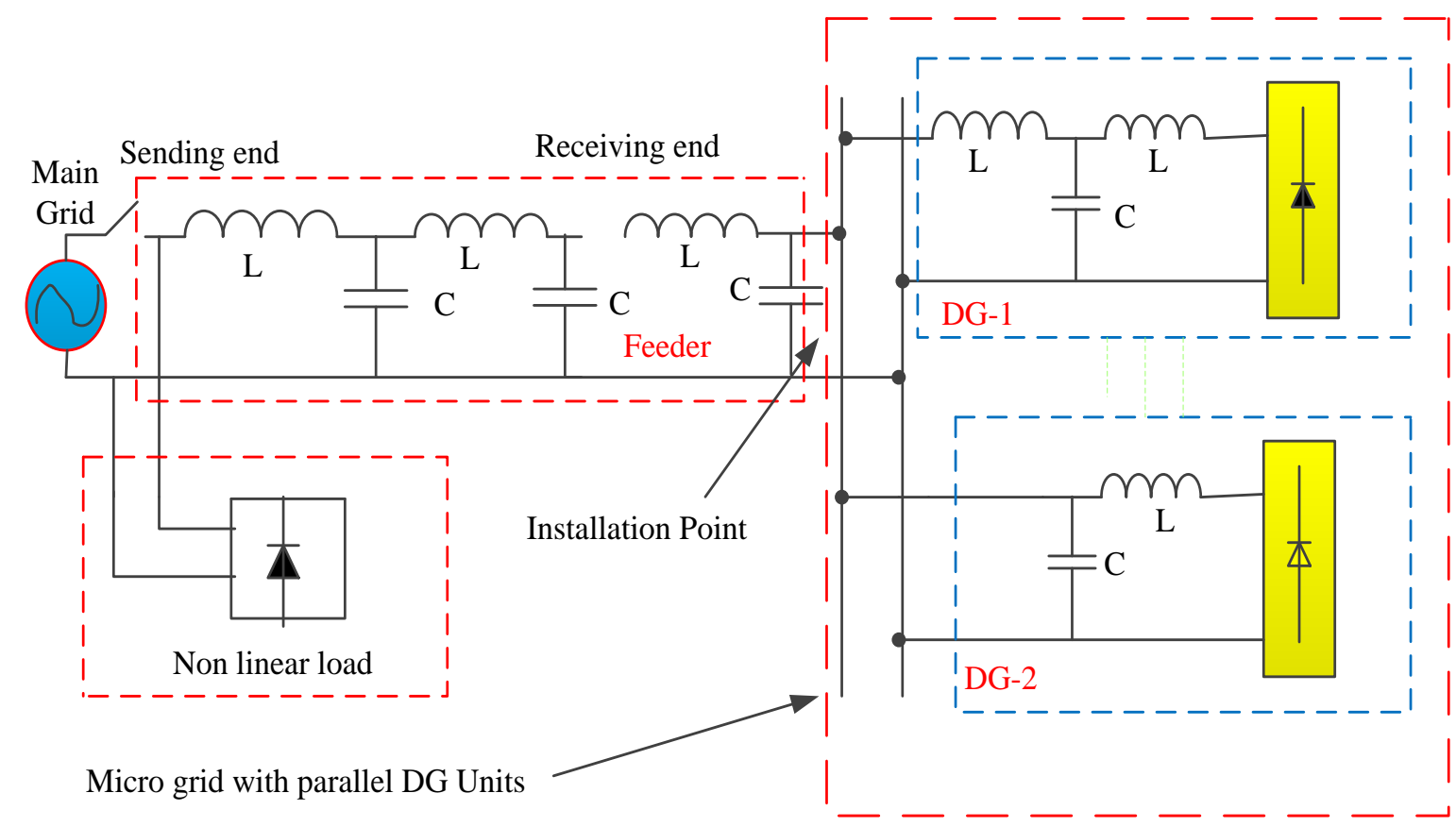

Figure 1. Simplified one-line diagram of a single phase micro grid service.

\subsection{Distributed Parameter Model in Grid-Tied Operation}

For a protracted feeder, as illustrated in Figure 1, a lumped parameter model isn't able to describe its resonance propagation characteristics. Alternatively, the distributed parameter model was mentioned in [3] and [6], where the voltage distortions at PCC induce a harmonic voltage standing wave on the feeders. Where the kth PCC harmonic voltage is assumed to be stiff and V pcck, Vk (x)and Ik (x) square measure the feeder kth harmonic voltage and harmonic current at position $\mathrm{x}$ and he length of the feeder is 1.

It is easy to obtain the harmonic voltage-current standing wave equations at the harmonic order $\mathrm{k}$ as

$$
\begin{aligned}
& V_{k}(x)=A e^{-\gamma x}+B e^{\gamma x} \\
& I_{K}(x)=\frac{1}{Z}\left(A e^{-\gamma x}-B e^{\gamma x}\right)
\end{aligned}
$$


Where $\mathrm{A}$ and $\mathrm{B}$ are constants, which are determined by feeder boundary conditions. $\mathrm{z}$ and $\gamma$ are the characteristic impedance [3] of the feeder without considering the line resistance as

$$
\begin{aligned}
& Z=\sqrt{\frac{L}{C}} \\
& \gamma=j k \omega_{f} \sqrt{L C}
\end{aligned}
$$

Where $\omega_{\mathrm{f}}$ is the fundamental angular frequency and $\mathrm{L}$ and $\mathrm{C}$ are the feeder equivalent inductance and shunt capacitance per kilometer, respectively.

1) DG Units with CCM and R-APF Control: To determine the boundary conditions of the feeder, the equivalent harmonic impedance $\left(\mathrm{Z}_{\mathrm{ADk}}\right)$ of the DG unit must be derived. First, the current reference $\left(\mathrm{I}_{\mathrm{ref}}\right)$ of a CCM-based DG unit can be obtained as

$$
\begin{aligned}
& I_{\text {ref }}=i_{\text {reff }}-I_{A D} \\
& =I_{\text {reff }}-\frac{H_{D}(S) \cdot V(l)}{R_{V}}
\end{aligned}
$$

where $I_{\text {reff }}$ is the fundamental current reference for DG unit power control, IAD is the harmonic current reference for system resonance compensation, $\mathrm{V}(\mathrm{l})$ is the measured installation point voltage at the receiving end of the feeder, $\mathrm{H}_{\mathrm{D}}(\mathrm{s})$ is the transfer function of a harmonic detector, which extracts the harmonic components of the installation point voltage, and $\mathrm{R}_{\mathrm{V}}$ is the command virtual resistance.

$$
\begin{aligned}
& \omega_{D G}=\omega_{f}+D_{P} \cdot\left(P_{r e f}-P_{L P F}\right) \\
& E_{D G}=E+D_{q} \cdot\left(Q_{r e f}-Q_{L P F}\right)+\frac{K_{Q}}{S}\left(Q_{r e f}-Q_{L P F}\right)
\end{aligned}
$$

where $\omega_{\mathrm{f}}$ and $\omega_{\mathrm{DG}}$ are the nominal and reference angular frequencies. $\mathrm{E}$ and $\mathrm{E}_{\mathrm{DG}}$ are the nominal and reference DG voltage magnitudes. $P_{\mathrm{LPF}}$ and $\mathrm{Q}_{\mathrm{LPF}}$ are the measured power with low pass filtering. Dp and Dq are the droop slopes of the controller

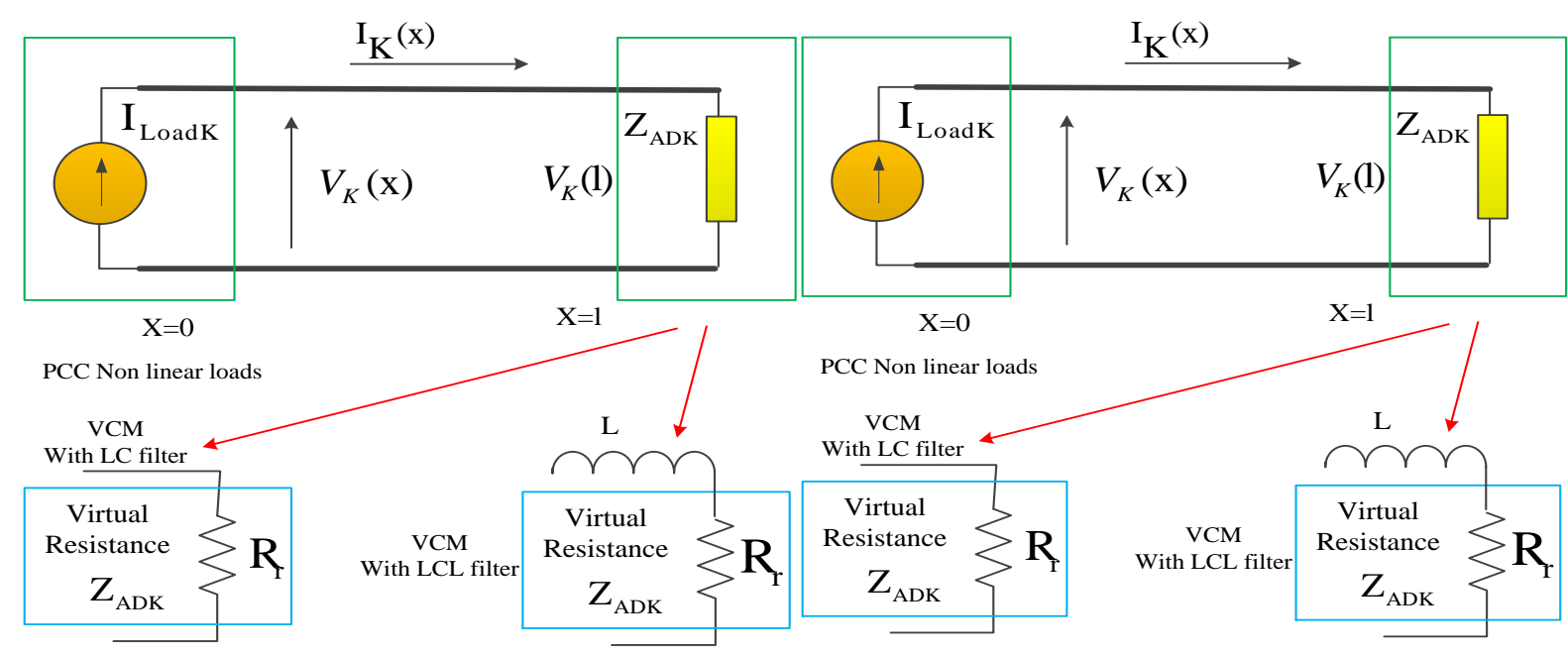

Figure 2. Equivalent circuit of a single gridconnected DG unit at the kth harmonic frequency
Figure 3. Equivalent circuit of a single islanding DG unit at the kth harmonic frequency

Note that with the integral control to regulate the DG unit voltage magnitude in (7), the steady-state reactive power control error in the grid tied operation is zero. Once the voltage magnitude reference and the frequency reference are determined, the ripple-free, instantaneous voltage reference $\left(\mathrm{V}_{\text {reff }}\right)$ can be easily 
obtained. The equivalent impedance of VCM-based DG unit with an LC filter has already been tuned to be resistive, by adding a DG line current $\left(\mathrm{I}_{\mathrm{DG}}\right)$ feed-forward term to the voltage control reference. Although previous VCM-based DG equivalent impedance shaping techniques, mainly focus on improving the power sharing performance of multiple DG units in an islanding micro grid, similar idea can also be used to mitigate the harmonic propagation along the feeder as

$$
\begin{aligned}
& V_{r e f}=V_{r e f f}-V_{A D} \\
& =V_{r e f}-R_{V} \cdot\left(H_{D}(S) . I_{D G}\right)
\end{aligned}
$$

Where $V_{\text {reff }}$ is the fundamental voltage reference derived from droop control in (6) and (7), $V_{A D}$ is the harmonic voltage reference for DG unit harmonic impedance shaping, $\mathrm{I}_{\mathrm{DG}}$ is the measured DG unit line current as shown in Figure $1, \mathrm{H}_{\mathrm{D}}(\mathrm{s})$ is the transfer function of a harmonic detector, which extracts the harmonic components of $\mathrm{DG}$ unit line current, and $\mathrm{R}_{\mathrm{V}}$ is the virtual resistance command. Since a gridconnected DG unit using either CCM or VCM can be modeled by an equivalent harmonic impedance at the receiving end of the feeder, the following boundary conditions can be obtained:

$$
\begin{aligned}
& \frac{V_{k}(l)}{I_{k}(l)}=Z_{A D K} \\
& V_{k}(0)=V_{P C C K}
\end{aligned}
$$

By solving (1), (2), (9), and (10), the harmonic voltage propagation at the harmonic order $\mathrm{k}$ can be expressed as

$$
V(x)_{k}=\frac{Z_{A D K} \cos h(\gamma(l-x))+z \sin h(\gamma(l-x))}{Z_{A D K} \cos h(\gamma l)+z \sin h(\gamma l)} V_{p c c k}
$$

With the obtained equation in (11), the impact of the DG active damping scheme to the harmonic voltage propagation along the feeder can be easily analyzed. Note that when the micro grid feeder is purely RL impedance, the DG unit can still work as a virtual harmonic resistor at the end of the feeder. In this case, the DG unit has the capability of absorbing some PCC nonlinear load current if it is designed and controlled properly

\subsection{Distributed Parameter Model in Islanding Operation}

The previous section focuses on the analysis of grid-tied DG units. For an islanding micro grid system, the VCM operation of DG units is needed for direct voltage support. To the best of the authors' knowledge, the quantitative analysis of islanding micro grid harmonic propagation is not available. When only a single DG unit is placed in the islanding system, constant voltage magnitude and constant frequency (CVMCF) control can be used. Multiple DG units in the micro grid as shown in Figure 1, the droop control method in (6) and (7) [by setting KQ $=0$ in (7)] shall be employed to realize proper power sharing among these DG units. Considering the focus of this section is to investigate the harmonic voltage damping in a standalone islanding system, a single DG unit at the receiving end of the feeder is considered. The circuit model of an islanding system at the harmonic order $\mathrm{k}$ is illustrated in Figure 3, With the knowledge of boundary conditions at both sending and receiving ends as

$$
\begin{aligned}
& I_{k}(0)=I_{L o a d k} \\
& \frac{V_{k}(l)}{I_{k}(l)}=Z_{A D K}
\end{aligned}
$$

The $\mathrm{k}$ th harmonic voltage distortion along the feeder can be obtained

$$
V_{k}(x)=\left(\frac{e^{-\gamma x}}{1+\left(\left(z-Z_{A D K)} /\left(z+Z_{A D k}\right)\right) e^{2 \gamma l}\right.}-\frac{e^{\gamma x}}{1+\left(\left(z+\frac{\left.Z_{A D K}\right)}{z-Z_{A D k}}\right)\right) z I_{L o a d}}\right)
$$


From (14), it can be noticed that the voltage propagation in an islanding system harmonic is also related to the DG-unit equivalent harmonic impedance. In order to maintain satisfied voltage quality, the equivalent harmonic impedance of islanding DG units shall also be properly designed.

\section{REALIZATION OF VIRTUAL DAMPING IMPEDANCE THROUGH DG VOLTAGE CONTROL}

It has been clarified that an LCL filter grid-side inductor (L2) can affect the performance of distribution system harmonic suppression, especially in the case of multiple DG units. In order to compensate the impact of LCL filter grid-side inductor, the harmonic voltage damping scheme as shown in (8) shall be further improved.

\subsection{Conventional Voltage Tracking}

First, a negative virtual inductor can be produced by VCM. Accordingly, the modified voltage reference is obtained as

$$
\begin{aligned}
& V_{\text {ref }}=V_{\text {reff }}-V_{A D-} V_{\text {comp }} \\
& V_{\text {ref }}=R_{V}-H_{D}(s) \cdot I_{D G}-s\left(-L_{2}\right) \cdot H_{D}(s) \cdot I_{D G}
\end{aligned}
$$

By further looking into (15), one can find that the implementation of virtual inductor involves derivative operation, which may adversely amplify system background noises. For instance, if a band-stop filter is selected to filter out the fundamental components as

$$
H_{D}(S)=1-\frac{2 \omega_{B P} S}{S^{2}+2 \omega_{B P} S+\omega_{f}^{2}}
$$

Where $\omega_{\mathrm{BP}}$ is the cutoff bandwidth of the band-stop filter, the voltage compensation term $\mathrm{V}_{\text {Comp }}$ in (15) can be expressed as

$$
V_{c o m p}=S\left(-L_{2}\right) \cdot H_{D}(S) I_{D G}=\left(-s L_{2}+\frac{2 \omega_{B P} L_{2} S^{2}}{S^{2}+2 \omega_{B P} S+\omega_{f}^{2}}\right) \cdot I_{D G}
$$

The diagram of a DG unit with negative virtual inductor control is shown in Figure 8. As illustrated, the DG unit is interfaced to long feeder with an LCL filter.

\subsection{Implementation of Nonlinear Virtual Capacitor}

In this subs ection, a well understood double-loop voltage controller is selected for DG unit voltage tracking. In the outer filter capacitor voltage control loop, the proportional and multiple resonant (PR) controllers are used as

$$
I_{\text {inner }}=G_{\text {outer }}(s) \cdot\left(V_{\text {ref }}-V_{C}\right)=\left(K_{p}+\sum_{K} \frac{2 k_{i k} \omega_{c} k^{2}}{S^{2}+2 \omega_{c} k^{2}+(k \omega f)^{2}}\right) \cdot\left(V_{\text {ref }}-V_{C}\right)
$$

where $K_{P}$ is the outer loop proportional gain, $K_{i k}$ is the gain of resonant controller at fundamental and selected harmonic frequencies, $\omega_{\mathrm{ck}}$ is the cutoff bandwidth, and inner is the control reference for the inner control loop. In the inner loop controller $\left(\mathrm{G}_{\text {Inner }}(\mathrm{s})\right)$, a simple proportional controller $\left(\mathrm{K}_{\text {inner }}\right)$ is employed and the inverter output current $\left(\mathrm{I}_{\text {inv }}\right)$ is measured as the feedback. 


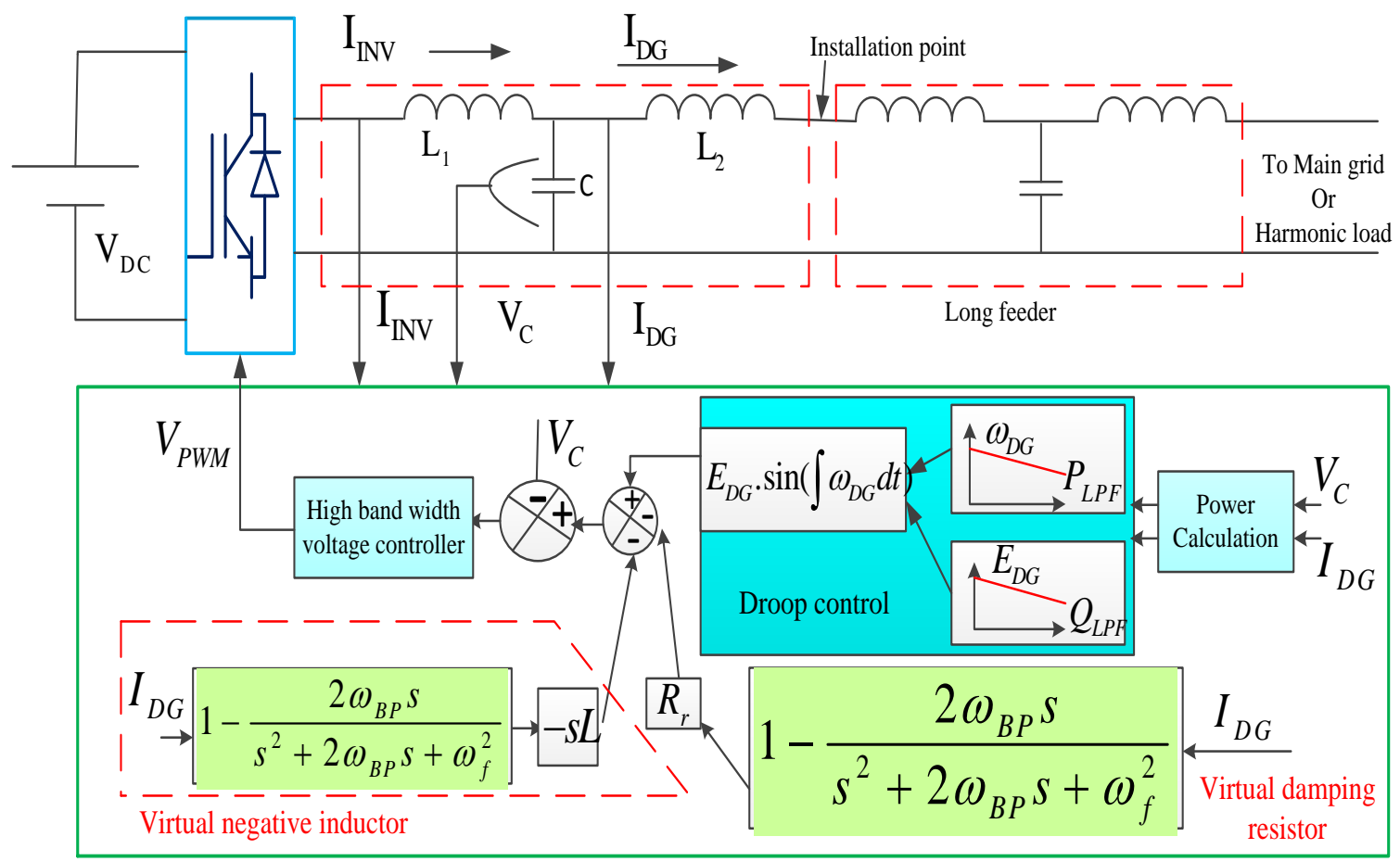

Figure 4. Mitigation of distribution feeder harmonic propagation using virtual resistor and virtual negative

This is because the impedance of a capacitor also has $90^{\circ}$ lagging phase angle, which is the same as that in a negative inductor.

$$
L_{2}(\omega f t)-\frac{1}{C_{v k}(\omega f t)}=0
$$

Where $\omega_{\mathrm{f}}$ is the fundamental angular frequency and $\mathrm{C}_{\mathrm{V}} \mathrm{t}$ is the command capacitance at the harmonic order $\mathrm{t}$.

Table 1. DG Unit Parameters

\begin{tabular}{ll}
\hline Control parameter & Value \\
\hline Rated voltage & $\mathrm{RMS} 60 \mathrm{~V}$ \\
Rated frequency & $\mathrm{F}=60 \mathrm{~Hz}$ \\
Droop coefficients & $\mathrm{Dp}=1 / 300 ; \mathrm{Dp}=1 / 300 ; \mathrm{KQ}=1 / 30$ \\
Proportional gain & $\mathrm{Kp} 1=0.11$ \\
Resonant gain & $\mathrm{Kif}=20, \mathrm{Ki} 3=15, \mathrm{Ki} 5=15, \mathrm{Ki} 9=10 ;$ \\
Cut off frequency & $\omega_{c k}=4 \mathrm{rad} / \mathrm{s} \quad(\mathrm{K}=1,3,5,7$ and 9$)$ \\
Inner loop controller & $K_{\text {inner }}=20$ \\
DC link voltage & $V_{d c}=240 \mathrm{v}$ \\
Sampling and Switching frequency & $12 \mathrm{KHZ}$ \\
Circuit parameter & $\mathrm{Value}$ \\
LCL filter & $\mathrm{L} 1=2 \mathrm{mH} \mathrm{L} 2=3.5 \mathrm{mH} \mathrm{Cf}=20 \mu \mathrm{F}$ \\
LC filter & $\mathrm{L} 1=2 \mathrm{mH} \mathrm{L} 2=0 \mathrm{mH} \mathrm{Cf}=20 \mu F$ \\
Command virtual resistance & $R_{V}=5.5 \omega \quad R_{v}=11 \omega$ \\
\hline
\end{tabular}

Afterwards, the voltage drops on the nonlinear virtual capacitor can be obtained as

$$
V_{c o m p}=\sum_{t} \frac{1}{s C_{v t}} \cdot I_{D G t}=\sum_{t} \frac{1}{s C_{v t}} \cdot\left(H_{D t}(s) \cdot I_{D G t}\right)
$$


Where $\mathrm{H}_{\mathrm{Dt}}(\mathrm{s})$ is the harmonic detector to detect the th DG harmonic current $\mathrm{I}_{\mathrm{DGt}}$. It can also be seen that parallel resonant controllers used in the outer loop voltage control in (17) are essentially a set of bandpass filters with narrow bandwidth $\omega_{\mathrm{ck}}$ and amplified magnitudes $\mathrm{K}_{\mathrm{ik}}$. Indeed, the harmonic selective capability has already been embedded in the resonant controllers.

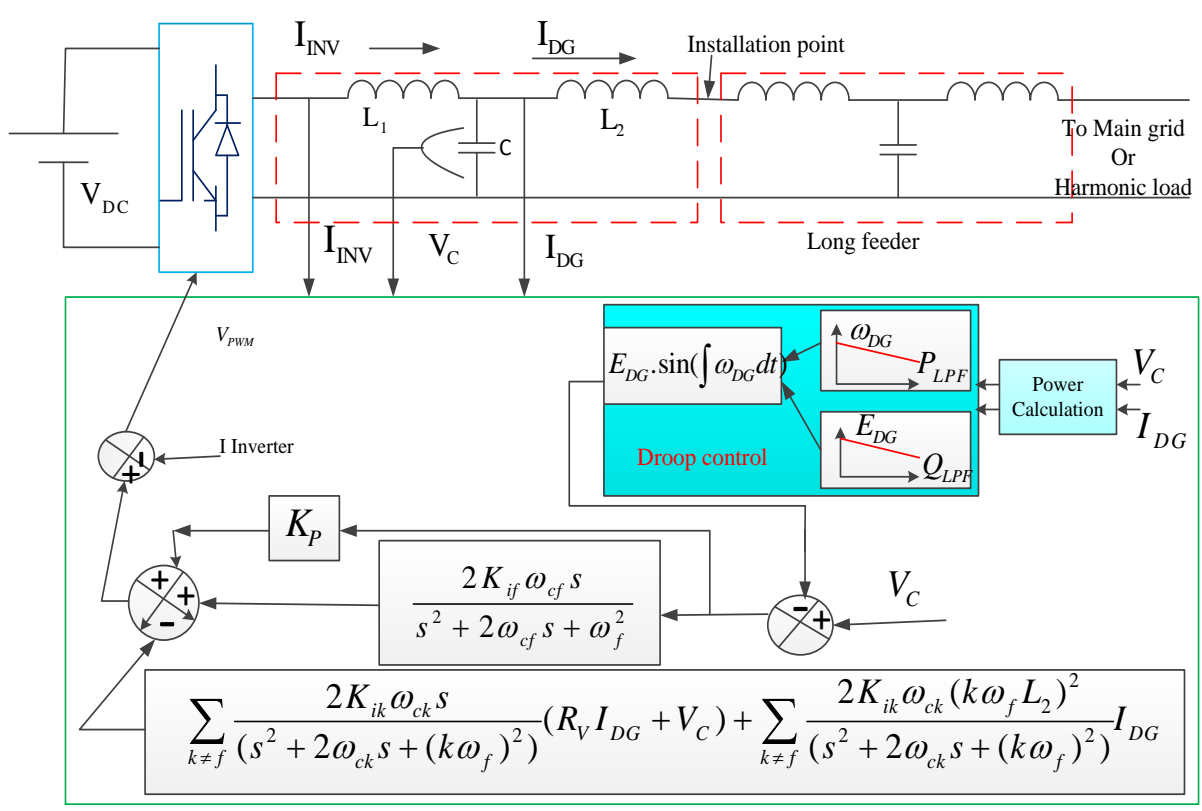

Figure 5. Mitigation of harmonic propagation using virtual resistor and nonlinear virtual capacitor

\section{VERIFICATION OF RESULTS}

Simulated results have been obtained from a single-phase low voltage micro grid. To emulate the behavior of six kilometers feeder with distributed parameters, a DG unit with an LCL filter is connected to PCC through a ladder network with six identical LC filter units as shown in Figure 1.

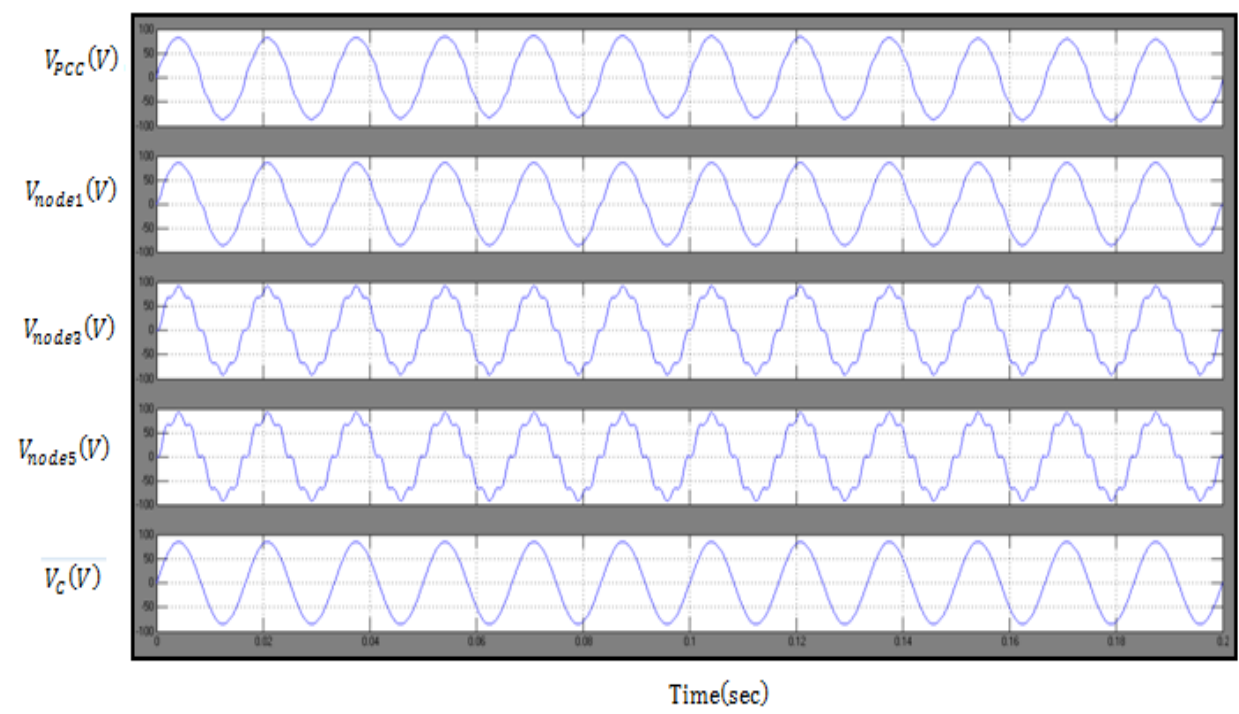

Figure 6. Harmonic voltage amplification during a single DG unit grid connected operation (without damping) [from upper to lower: (a) PCC voltage (THD =4.0\%); (b) node 1 voltage (THD = 4.56\%); (c) node 3 voltage $(\mathrm{THD}=10.91 \%)$; $(\mathrm{d})$ node 5 voltage $(\mathrm{THD}=12.59 \%) ;(\mathrm{e})$ DG unit filter capacitor voltage $(\mathrm{THD}=$ $0.38 \%)$ ] 


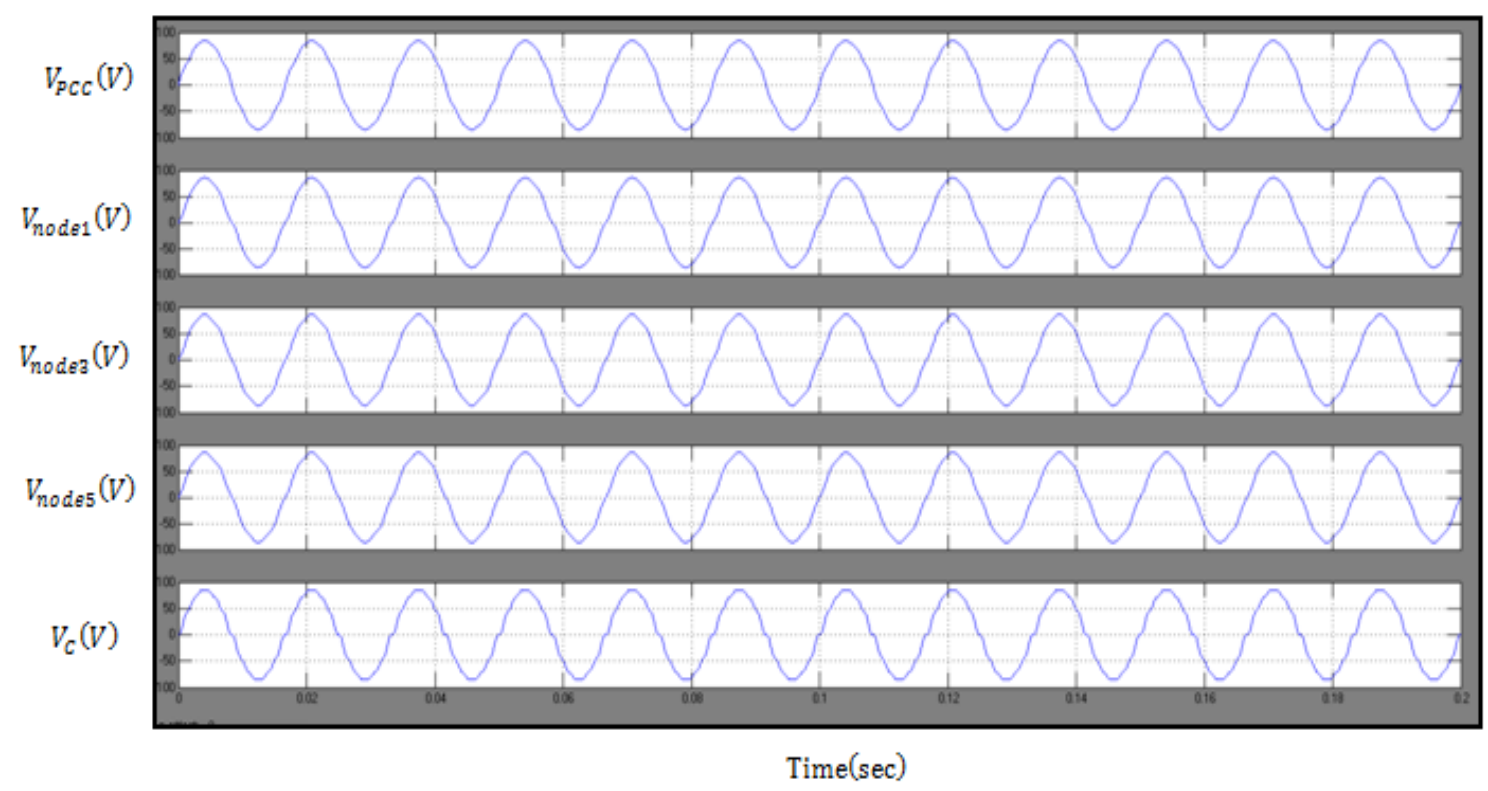

Figure. 7. Harmonic voltage amplification during a single DG unit grid connected operation (with virtual nonlinear capacitor and resistor based active damping) [from upper to lower: (a) PCC voltage (THD = 4.0\%); (b) node 1 voltage $(\mathrm{THD}=4.1 \%)$; (c) node 3 voltage $(\mathrm{THD}=3.7 \%)$; (d) node 5 voltage $(\mathrm{THD}=3.2 \%)$; and (e) DG unit filter capacitor voltage $(\mathrm{THD}=5.4 \%)$

\subsection{Single DG Unit Grid-Tied Operation}

At first, the performance of a grid-connected DG unit with an LCL filter is examined. The PCC voltage in this simulation is stiff and it has $2.0 \%$ distortion at each lower order harmonic frequency (3rd, 5th, 7th, and 9th harmonics).

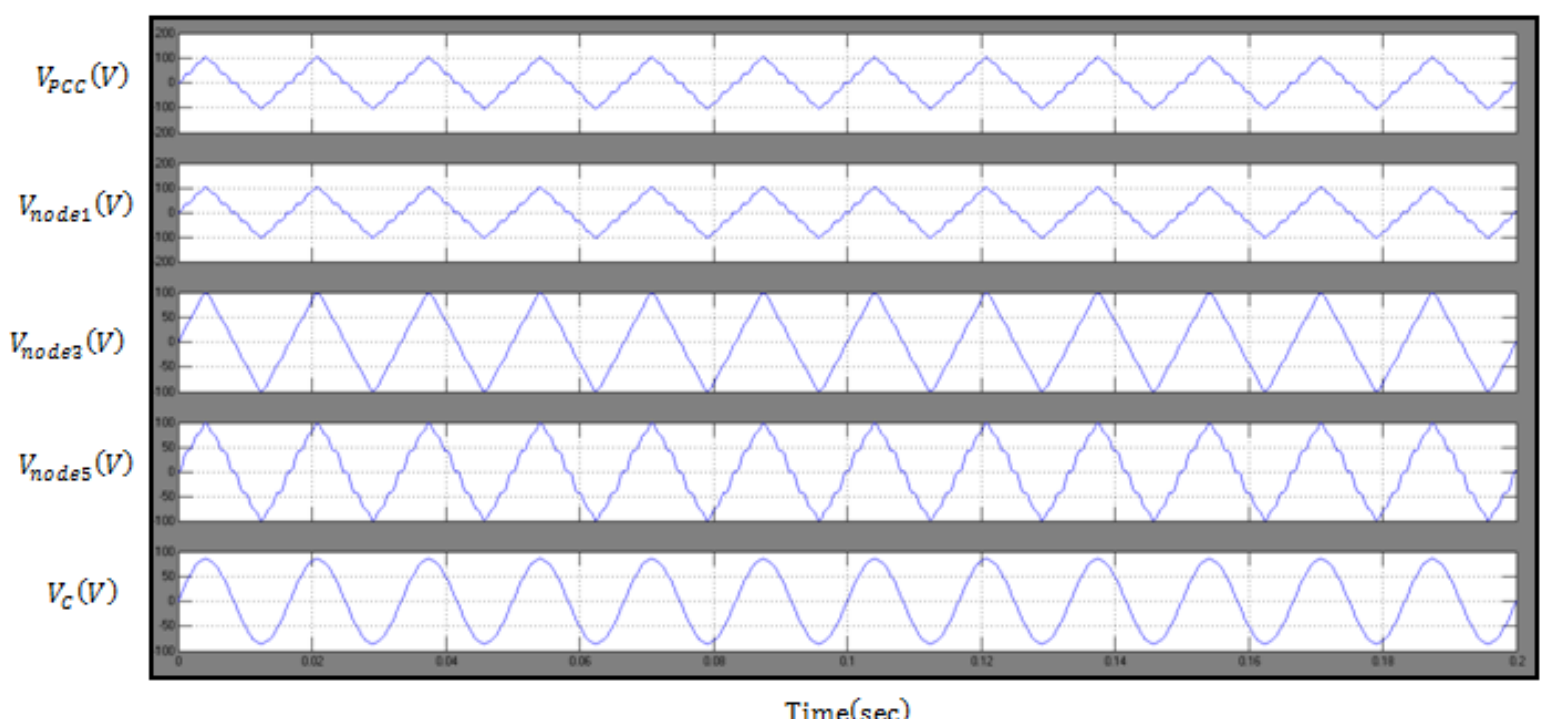

Figure 8. Harmonic voltage amplification during a single DG unit islanding operation (without damping) [from upper to lower: (a) PCC voltage (THD =15.2\%); (b) node 1 voltage (THD =14.7\%); (c) node 3 voltage $(\mathrm{THD}=11.9 \%) ;(\mathrm{d})$ node 5 voltage $(\mathrm{THD}=10.5 \%)$; and $(\mathrm{e})$ DG unit filter capacitor voltage $(\mathrm{THD}=$ $1.6 \%)]$ 
Table 2. Harmonic Spectrum of A Grid-Connected Microgrid Without Active Damping

\begin{tabular}{|c|c|c|c|c|c|c|c|c|}
\hline & $3^{\text {rd }}$ Harmonic & $5^{\text {th }}$ & Harmonic & $\begin{array}{c}7^{\text {th }} \\
\text { Harmonic }\end{array}$ & $9^{\text {th }}$ harmonic & $\begin{array}{c}11^{\text {th }} \\
\text { Harmonic }\end{array}$ & $\begin{array}{c}13^{\text {th }} \\
\text { Harmonic }\end{array}$ & THD \\
\hline PCC voltage & $2.00 \%$ & & $2.00 \%$ & $2.00 \%$ & $2.00 \%$ & $0 \%$ & $0 \%$ & $4.00 \%$ \\
\hline Node 1Voltage & $1.91 \%$ & & $2.41 \%$ & $2.89 \%$ & $1.31 \%$ & $0.05 \%$ & $0.03 \%$ & $4.56 \%$ \\
\hline Node 3Voltage & $1.65 \%$ & & $2.92 \%$ & $10.37 \%$ & $0.74 \%$ & $0.03 \%$ & $0.04 \%$ & $10.91 \%$ \\
\hline Node 5 Voltage & $1.24 \%$ & & $2.57 \%$ & $12.31 \%$ & $2.07 \%$ & $0.01 \%$ & $0.02 \%$ & $12.59 \%$ \\
\hline DG voltage & $0.02 \%$ & & $0.04 \%$ & $0.10 \%$ & $0.14 \%$ & $0.15 \%$ & $0.2 \%$ & $0.38 \%$ \\
\hline
\end{tabular}

Table 3. Harmonic Spectrum of an Islanding Micro Grid Without Active Damping

\begin{tabular}{|c|c|c|c|c|c|c|c|}
\hline & $3^{\text {rd }}$ harmonic & $5^{\text {th }}$ Harmonic & $\begin{array}{c}7^{\text {th }} \\
\text { Harmonic }\end{array}$ & $9^{\text {th }}$ Harmonic & $\begin{array}{c}11^{\text {th }} \\
\text { Harmonic }\end{array}$ & $\begin{array}{c}13^{\text {th }} \\
\text { Harmonic }\end{array}$ & THD \\
\hline PCC voltage & $13.19 \%$ & $2.95 \%$ & $0.29 \%$ & $1.66 \%$ & $6.58 \%$ & $0.54 \%$ & $15.19 \%$ \\
\hline Node 1Voltage & $11.96 \%$ & $3.68 \%$ & $0.39 \%$ & $1.07 \%$ & $6.62 \%$ & $1.46 \%$ & $14.67 \%$ \\
\hline Node 3Voltage & $10.05 \%$ & $4.35 \%$ & $1.45 \%$ & $0.66 \%$ & $1.09 \%$ & $0.61 \%$ & $11.93 \%$ \\
\hline Node 5Voltage & $7.54 \%$ & $3.83 \%$ & $1.73 \%$ & $1.76 \%$ & $5.98 \%$ & $0.86 \%$ & $10.51 \%$ \\
\hline DG voltage & $0.10 \%$ & $0.05 \%$ & $0.02 \%$ & $0.45 \%$ & $1.43 \%$ & $0.2 \%$ & $1.60 \%$ \\
\hline
\end{tabular}

Table 4. DG Unit Parameters

\begin{tabular}{ll}
\hline Control parameter & Value \\
\hline Rated voltage & RMS 60V \\
Rated frequency & $\mathrm{F}=60 \mathrm{~Hz}$ \\
Droop coefficients & $\mathrm{Dp}=1 / 300 ; \mathrm{Dp}=1 / 300 ; \mathrm{K}_{\mathrm{Q}}=1 / 30$ \\
Proportional gain & $\mathrm{Kp} 1=0.11$ \\
Resonant gain & $\mathrm{Kif}=20, \mathrm{Ki} 3=15, \mathrm{Ki} 5=15, \mathrm{Ki} 9=10 ;$ \\
Cutoff frequency & $\omega_{c k}=4 \mathrm{rad} / \mathrm{s}(\mathrm{K}=\mathrm{f}, 3,5,7$ and 9$)$ \\
Inner loop controller & $K_{\text {inner }}=20$ \\
DC link voltage & $V_{d c}=240 \mathrm{v}$ \\
Sampling and Switching frequency & $12 \mathrm{KHZ}$ \\
Circuit parameter & $\mathrm{Value}$ \\
LCL filter & $\mathrm{L} 1=2 \mathrm{mH} \mathrm{L} 2=3.5 \mathrm{mH} \mathrm{Cf}=20 \mu F$ \\
LC filter & $\mathrm{L} 1=2 \mathrm{mH} \mathrm{L} 2=0 \mathrm{mH} \mathrm{Cf}=20 \mu F$ \\
Command virtual resistance & $R_{V}=5.5 \omega$ \\
\hline
\end{tabular}

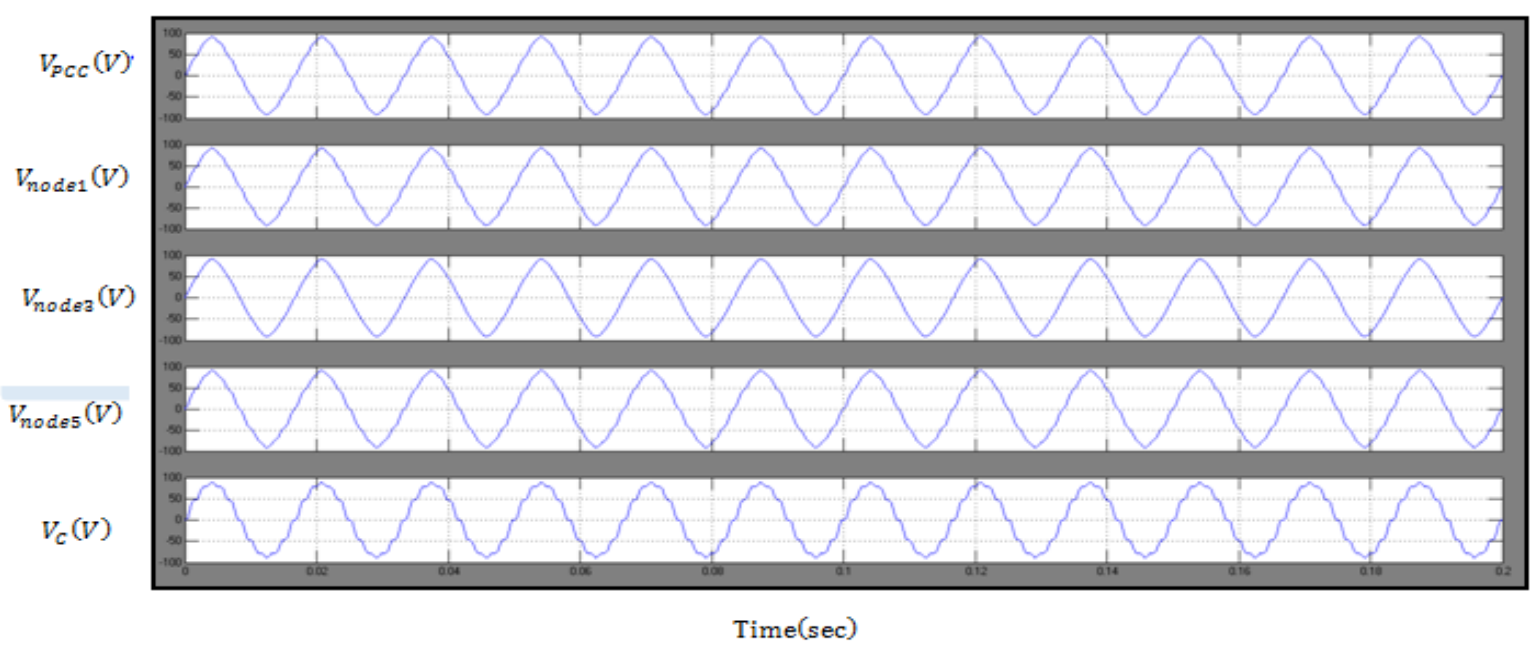

Figure 9. Harmonic voltage amplification during a single DG unit islanding operation (with virtual nonlinear capacitor and resistor based active damping) [from upper to lower: (a) PCC voltage (THD =6.1\%); (b) node 1 voltage $(\mathrm{THD}=6.0 \%)$; (c) node 3 voltage $(\mathrm{THD}=5.2 \%)$; $(\mathrm{d})$ node 5 voltage $(\mathrm{THD}=5.3 \%)$; and (e) DG unit filter capacitor voltage $(\mathrm{THD}=7.1 \%)$ ]

\subsection{Single DG Unit Grid-Tied Operation}

In addition to grid-connected operation, the performance of a single DG unit in islanding operation is also investigated. In this case, the PCC lad is a single-phase diode rectifier and it is supplied by the DG unit through long feeder. When the conventional VCM without damping is adopted, the performance of the 
system is obtained in Figure 8. Similar to the grid-tied operation, the voltage waveforms at PCC, nodes 1, 3, and 5, and DG unit filter capacitor are shown from channels (a) to (e), respectively.

\subsection{Multiple DG Units Grid-Tied Operation}

To verify the circulating harmonic current between multiple DG units, two grid-connected DG units at the same power rating are placed at the receiving end of the feeder in this simulation, DG unit 1 is interfaced to the feeder receiving end with an $L C$ filter while DG unit 2 has an LCL filter.
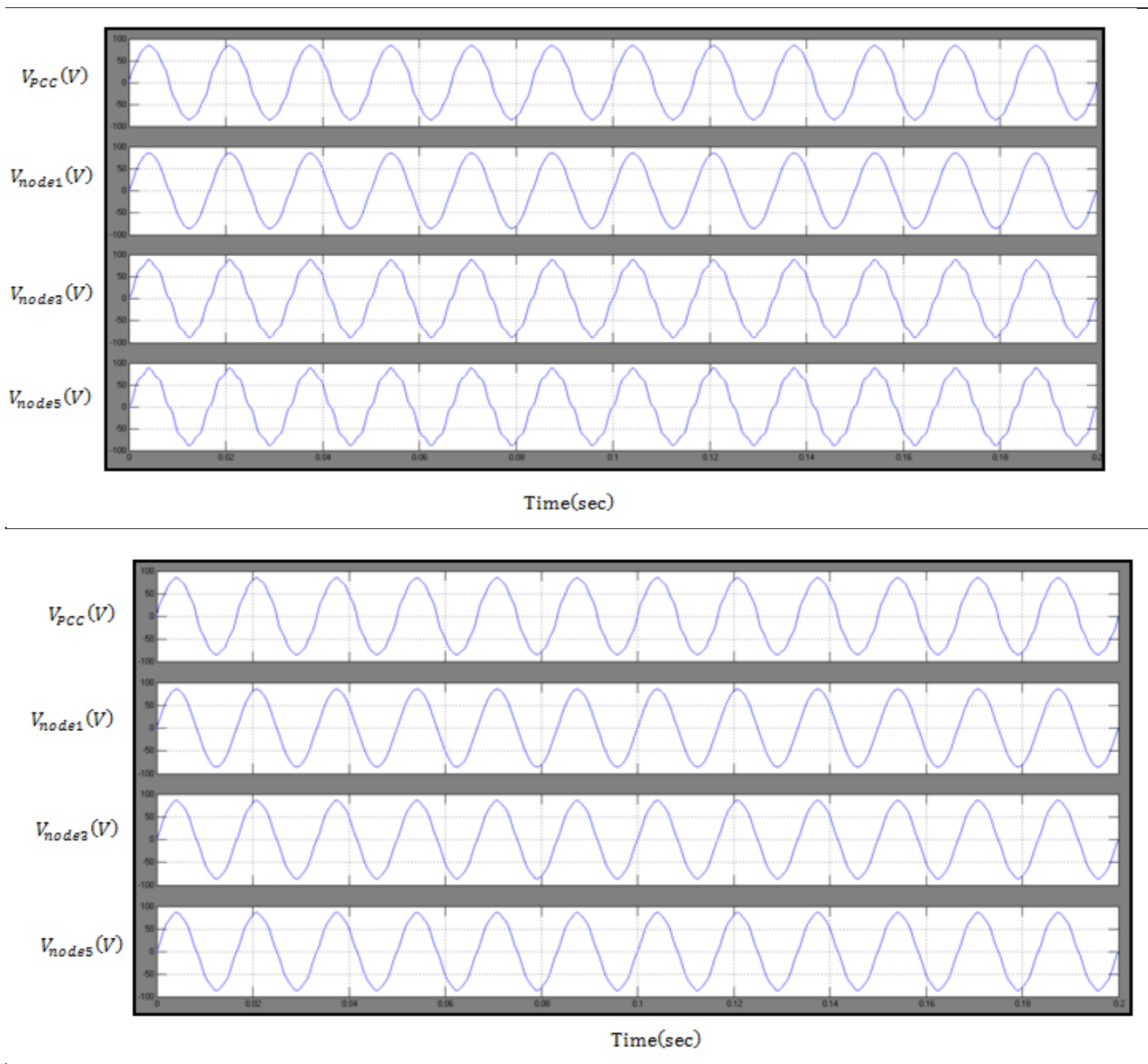

Figure. 10. Harmonic voltage amplification along the feeders (grid-tied operation of two parallel DG units).

The PCC voltage harmonics are selected to be the same as that in Figure 9. When both DG units are operating without any virtual impedance control, DG unit 1 essentially behaves as short circuit at the harmonics and DG unit 2 works as an equivalent inductor $L 2$, The voltage waveform along the feeder is shown in the first column of Figure 10. In this case, there are some voltage distortions at the nodes 1 and 3. When only virtual resistor regulation using (8) is applied to both DG units, it can be seen from the second column of Figure 14 that harmonic voltage distortion are mitigated. 


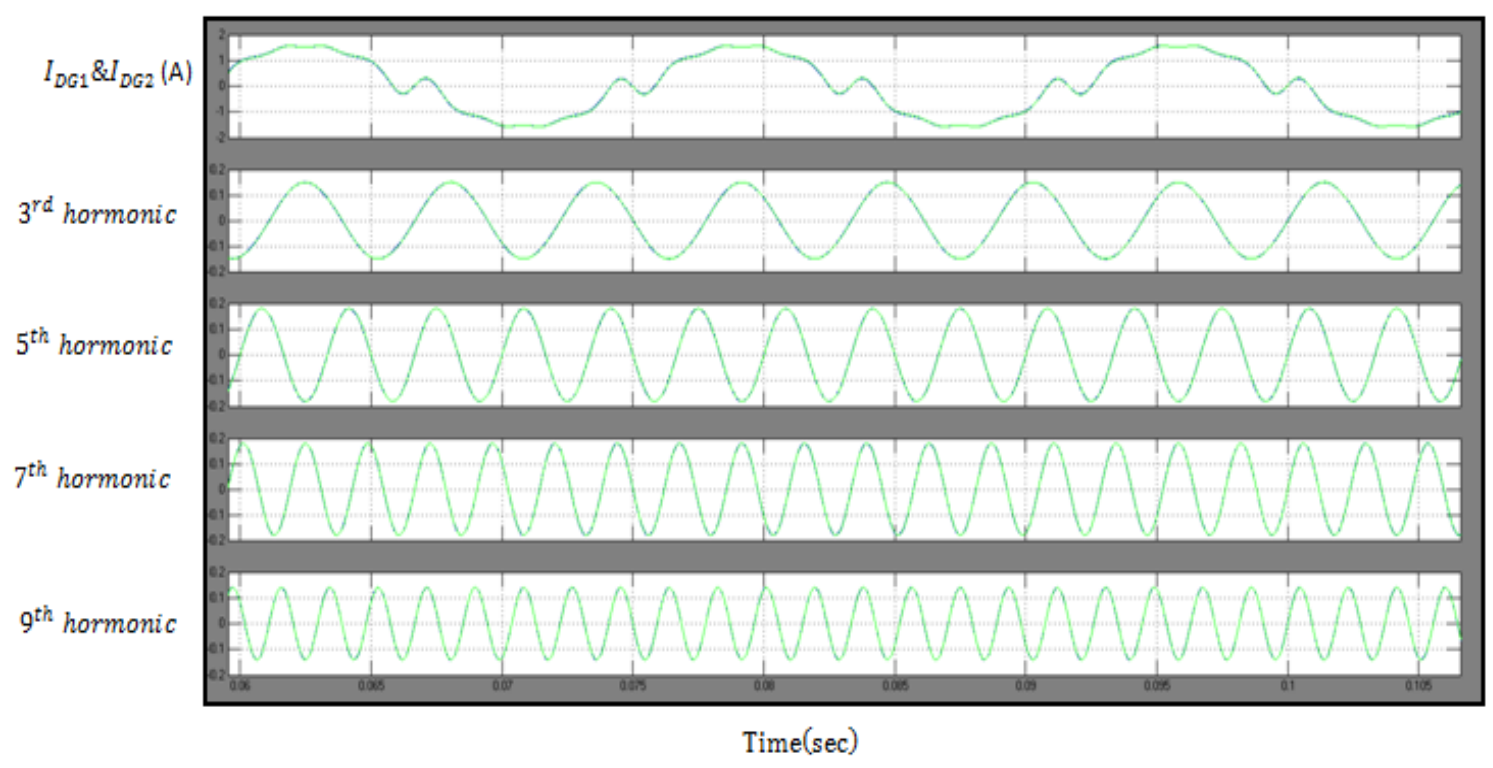

Figure 11. DG unit 1 and DG unit 2 line currents and their harmonic components (grid-tied operation of two parallel DG units)

Although the difference between the first and second columns of Figure 10 is not very obvious, the harmonic circulating current between parallel DG units can be noticeable. When both of the DG units are controlled by (8), the system appears some harmonic circulating currents as shown in the first column of Figure 10. These results agree with the discussion in Figures 6 and 7. Moreover, when the nonlinear virtual capacitor control is also applied to DG unit 2, the harmonic voltage drop on its $L C L$ filter grid-side inductor can be compensated and it also behaves as a virtual harmonic resistor. As a result, the harmonic circulating current among parallel DG units is effectively reduced. The improved harmonic current sharing performance is shown in the second column of Figure 11.

\section{CONCLUSION}

In this paper, the impacts of voltage-controlled and current-controlled distributed generation (DG) units to micro grid resonance propagation are compared. To actively mitigate the resonance using DG units, an enhanced DG unit component of the proposed nonlinear virtual impedance is employed to compensate the impact of dg unit LCL filter grid side inductor. The resistive element is responsible for active damping. With properly controlled dg equivalent harmonic impedance at chosen harmonic frequencies, the proposed method can even eliminate the harmonic circulating current among multiple dg units with mismatched output filter parameters. Here we are using the fuzzy controller compared to other controllers due to its accurate performance Comprehensive simulations are conducted to substantiate the validity of the proposed method.

\section{REFERENCES}

[1] H. Akagi, “Active harmonic filters," Proc. IEEE, vol. 93, no. 12, pp. 2128-2141, Dec. 2005.

[2] H. Akagi, H. Fujita, and K. Wada, "A shunt active filter based on voltage detection for harmonic termination for radial power distribution system,” IEEE Trans. Ind. Appl., vol. 35, no. 4, pp. 682-690, Jul./Aug. 1995.

[3] K. Wada, H. Fujita, and H. Akagi, "Consideration of a shunt active filter based on voltage detection for installation on a long distribution feeder," IEEE Trans. Ind. Appl., vol. 38, no. 4, pp. 1123-1130, Jul./Aug. 2002.

[4] P.-T. Cheng and T.-L. Lee, "Distributed active filter systems (DAFSs): A new approach to power system harmonics,” IEEE Trans. Ind. Appl., vol. 42, no. 5, pp. 1301-1309, Sep./Oct. 2016.

[5] Ch. Rami Reddy, K. Harinadha Reddy "A Passive Islanding Detection method for Neutral point clamped Multilevel Inverter based Distributed Generation using Rate of Change of Frequency Analysis” International journal of electrical and computer engineering, volume: 08, issue: 04, pp: 1967-1976, 2018.

[6] T.-L. Lee, J.-C.Li, and P.-T. Cheng, "Discrete frequency-tuning active filter for power system harmonics," IEEE Trans. Power Electron., vol. 24, no. 5, pp. 1209-1217, Apr. 2017.

[7] T.-L. Lee and S.-H.Hu, "Discrete frequency-tuning active filter to suppress harmonic resonances of closed-loop distribution power system," IEEE Trans. Power Electron., vol. 26, no. 1, pp. 137-148, Dec. 2010. 
[8] N. Pogaku and T. C. Green, "Harmonic mitigation throughout a distribution system: A distributed-generator-based solution," IEE Proc. Gener. Transmiss.Distrib., vol. 153, no. 3, pp. 350-358, May 2016.

[9] C. J. Gajanayake, D. M. Vilathgamuwa, P. C. Loh, R. Teodorescu, and F. Blaab jerg, "Z-source-inverter-based flexible distributed generation system solution for grid power quality improvement," IEEE Trans. Energy Convers., vol. 24, pp. 695-704, Sep. 2017.

[10] Y. W. Li, D. M. Vilathg amuwa, and P. C. Loh, "Design, analysis and real time testing of a controller for multi bus micro grid system,” IEEE Trans. Power Electron., vol. 19, no. 5, pp. 1195-1204, Sep. 2004

[11] Ch. Rami Reddy, K. Harinadha Reddy "Islanding detection for inverter based distributed generation with Low frequency current harmonic injection through Q controller and ROCOF analysis" Journal of electrical systems, volume: 14, issue: 02, pp: 179-191, 2018.

[12] J. He and Y. W. Li, "Analysis, design and implementation of virtual impedance for power electronics interfaced distributed generation,"'IEEE Trans. Ind. Appl., vol. 47, no. 6, pp. 2525-2538, Nov./Dec. 2011.

[13] Y. W. Li and C. N. Kao, "An accurate power control strategy for power electronics-interfaced distributed generation units operating in a lowvoltage multibus micro grid,'IEEE Trans. Power Electron., vol. 24, no. 12, pp. 2977-2988, Dec. 2009.

[14] J. M. Guerrero, L. G. Vicuna, J. Matas, M. Castilla, and J. Miret, “Output impedance design of parallel-connected UPS inverters with wireless load sharing control,’IEEE Trans. Ind. Electron., vol. 52, no. 4, pp. 1126-1135, Aug. 2005.

[15] J. M. Guerrero, L. G. Vicuna, J. Matas, M. Castilla, and J. Miret, "A wireless controller to enhance dynamic performance of parallel inverters in distributed generation systems," IEEE Trans. Power Electron., vol. 19, no. 4, pp. 1205-1213, Sep. 2014.

[16] Ch. Rami Reddy, K. Harinadha Reddy "Islanding detection method for inverter based distributed generation based on combined changes of ROCOAP and ROCORP” International journal of pure and applied mathematics, volume: 117, issue: 19, pp: 433-440, 2017.

[17] Ch. Rami Reddy, K. Harinadha Reddy "Islanding detection using DQ Transformation based PI Approach in integrated distributed generation" International journal of control theory and applications, volume: 10, issue: 05, pp: 679-690, 2017. 